\title{
Research on the Applications of Customer Segmentation Evaluation Model in the Exhibition Customer Administration
}

\author{
Bo Zhang ${ }^{1}$ \\ ${ }^{1}$ The Engineering \& Technical College of Chengdu University of Technology, Leshan City, Sichuan \\ Province, China
}

Keywords: exhibition industry; archives administration; countermeasure; innovation.

\begin{abstract}
The exhibition industry has continuously developed in China in the new era. In fact, the exhibition industry is divided into conference industry and exhibition industry in the world. The exhibition industry should be regarded as the beginning of service industry in the tertiary industry, which has always been closely related to other industries with the charactics of wide range and massive audience. In addition, the exhibition industry also has extensive and in-depth contact with other industries. It covers a lot of people. Nowadays, the economy continues to be weaker. In the case, being an emerging industry, the exhibition industry has naturally been impacted. Moreover, the people's requirements of the exhibition industry are becoming increasingly strict. Thus, to improve the competition of the exhibition market is necessary to improve the enterprises' exhibition budget, to focus on the quality and popularity of the exhibition products, think about how to develop new users and increase their experience, which is a great challenge to the enterprises. Therefore, the purpose of this study is to establish the evaluation model of customer segmentation and improve the relevant exhibition industry administration system, which can fully embody the value of the customer administration in the exhibition industry, and then expand on the practical research of the customer segmentation evaluation model in the exhibition customer administration.
\end{abstract}

\section{Introduction}

In this study, the exhibition customer administration is regarded as the focus. In the new era, this paper is based on the overall development of the current exhibition industry and makes in-depth analysis of the advantages of the current exhibition development. It also carries out a specific study on the existing problems and the situation and proposes proper solutions in order to complete the systematic study and establish the thinking mode of administration [1]. In this process, the exhibition administration constantly adapts to the new period under the special environment, which is the focus of our work and the direction of the entire industry. These will contribute to bring about a new future for the industry and to improve and broaden the research ideas of the innovation of the exhibition archives administration.

\section{The Exhibition Customer Administration in China in the New Era}

China exhibition customer administration. In China, the exhibition industry should be regarded as a new industry. Because of its unique advantages and the fact that the exhibition industry closely follows the trend of the times, it has gained good achievements in the competition in the market. At the same time, China's exhibition industry needs to enhance its ability and level in the process of optimizing the allocation and integrating the relevant resources. On the other hand, the exhibition customer administration should improve its competitiveness. In addition, the exhibition activities can also provide the sufficient employment opportunities to help the society and the local economic development.

The design of the customer segmentation evaluation model. The design of the customer segmentation evaluation model refers to the specific design of the customers' segmentation evaluation based on the market environment, the customers' own location, preferences, etc. According to the corresponding location, it also provides adequate supporting and help. On the other hand, the enterprises should continuously consider the customers' participation and the application 
value of the customers with different attributes is also different. This study makes full use of the customer segmentation evaluation model design. It can divide the customers into different classifications according to the types of users. From the users' perspective, the relevant exhibition enterprises can divide the customers' attribute into different types. Thus, the model can analyze the customers' value and divide them into the customers with high value, middle value and low value [2].

The problems in the exhibition customer administration in China. In the exhibition customer administration, there are many problems to be solved. At present, the primary problem is this emerging industry has naturally been impacted by the present economic conditions with continuous weakness. In addition, people's demands for the exhibition industry are increasingly stringent. Thus, in order to improve the competition of the exhibition market, it is necessary to improve the enterprises' budget in the exhibition. Meanwhile, they should focus on the exhibition quality and popularity, and then develop new users and increase their experience, which is a great challenge to the enterprises. At the same time, we should ensure that someone is responsible for each program, establish and improve the relevant administration system, ensure the work of the exhibition smoothly, determine the main direction of all the work, and further make clear of the working ideas. On the other hand, we can also put forward the innovative feasible countermeasures in order to ensure the ideas and the measures launched simultaneously, which is the direction the future [3]. In this study, the exhibition customer administration is regarded as the focus. In the new era, this paper is based on the overall development of the current exhibition industry and makes in-depth analysis of the advantages of the current exhibition development. It also carries out a specific study on the existing problems and the situation. In this process, the exhibition administration constantly adapts to the new period under the special environment, which is the focus of our work and the direction of the entire industry. These will contribute to bring about a new future for the industry and to improve and broaden the research ideas of the innovation of the exhibition archives administration [4].

\section{The Practical Study on the Customer Segmentation Evaluation Model in the Exhibition Customer Administration}

To identify the positioning needs of the target customers. First of all, in the early exhibition period to perfect the customer administration, all departments and personnel should consciously promote the exhibition concept of customer administration which is related to the customers' positioning requirements, identify the target customers, so that they can solve the problems in pre-exhibition customer administration. Some enterprises cannot obviously identify the target customers' positioning needs. Thud, they will not know what the customers really need, nor the evaluation of the customers' segmentation. They will take a blanket attitude, which will make a lot of customers uncomfortable for the customer administration scheme and the administration mode. This will lead to the fact that they cannot form cooperation with the enterprises and it will affect the future of the relationship between them. From this perspective, people involved in the various exhibitions, including the department leaders, should be clear about their own administration awareness, identify the positioning of the target customers' needs to ensure the smooth beginning of the entire campaign [5]. For example, if the relevant leaders begin to prepare the relevant exhibition information at the beginning of the event, make preparations for each customer and analyze their preferences. They will be successful to sign cooperation agreement with their partners and complete the practical study of this model.

To improve the customer segmentation evaluation mechanism. To certain extent, there is a very important relationship between the administration of the exhibition and the establishment of the exhibition administration demonstration base, the exhibition activities. In the present increasingly fierce competition, to improve the exhibition business administration and the quality of relevant activities is very necessary, which not only contributes to the perfect customer segmentation evaluation mechanism, but also ensures the quality of the exhibition activities which will enable the enterprises, the society and the public have greater benefits [6]. Thus, in the new period of the exhibition industry, to improve the evaluation mechanism of customer segmentation is a longer-term promotion of the present exhibition work, so as to further take advantages of the congenital exhibition 
industry under the new period and avoid the problems, which is the key task of the current solution. In the future, the enterprises' exhibition activities will set up high standards and strict requirements on the exhibition customer administration. The exhibition industry will not only stimulate the development of all aspects of China's economy, but also face the endless problems related to the mechanism. If the customer segmentation is regarded as an important part of the evaluation mechanism, the real implement will continuously contribute to the enterprises' development and improvement [7]. In other words, to improve the system of the customer segmentation evaluation mechanism is the task of each enterprise.

To make the discretization analysis of the relevant model. In fact, an important problem now facing in the customer administration exhibition is that the model has not enough discretization analysis, so that the exhibitors can use the corresponding processing system of the customer relationship administration and the discrete data processing and analysis technology to further practically research and analyze the related customer data, to identify the different types of the customers' requirements and to establish a sound system of the customer administration mechanism, which is the best way to solve this problem [8]. On the one hand, we can enable to provide the customers with corresponding data model and increase the efficiency of data improvement. At the same time, we can use the discretization analysis to analyze the original customers' data and the classification types, which can reduce the number of invalid attribute, and the processing model can also help the customers to strengthen the awareness of the people and make clear understanding of the exhibition administration. Through the data, we can enhance the discretization progressing of the whole model, which can not only improve the working enthusiasm of the employees, but also can enhance the users' value. Meanwhile, it will bring huge benefits for the entire industry, and strengthen the development of the whole industry.

\section{Conclusions}

Generally speaking, on the basis of the new period under this special environment, this paper researches on the current situations of the present exhibition activities, analyzes a series of innovative user administration and carries out abundant studies on it. By analyzing all kinds of difficult problems and user administration in the new period from many aspects, this paper aims to solve the problems and proposes useful suggestions, complete the strategic thinking of the system and establish the thinking mode of innovation research. In the customer segmentation mechanism of the exhibition industry, while establishing and improving the safety administration work in the exhibition industry, the enterprises should be based on the actual situation to make an analysis of the situation to develop a normative and systematic exhibition administration regulations. Under the new era, the exhibition market competition is becoming increasingly fierce. We should not only expand our activities to enhance the quality of the products, but also identify the target customers' needs. We should also improve the mechanism of customer segmentation evaluation, make discretizating analysis of the relevant model, make everyone responsible for safety and attach great importance to enterprise production. In addition, we should strengthen the personnel training of safety administration, supervision work. The whole industry should make full use of its own platform to establish the relevant production areas, so as to strengthen the informatization construction of exhibition industry, following the trend of the times and improving the efficiency and progress of the work. The author analyzes the advantages of the new era environment for the administration of exhibition users, the existing problems and the present status in the construction. In recent years, China's exhibition industry is booming, especially in some economically developed regions. The exhibition industry brings about more and more benefit and promotes the local economic development. Thus, the exhibition industry is naturally regarded a sunrise industry by a lot of people. In addition, the relevant activities carried out in the exhibition industry are different from those in other industries, mainly reflecting in the coverage of the wide audience. It is also closely related to the modern people's daily lives. Thus, on the other hand, people' requirements for the exhibition industry are becoming increasingly strict. In this process, we should attach great importance to simplify the process of the exhibition archive administration and constantly adapt to the new environment. The purpose of this 
study is to establish the evaluation model of customer segmentation and improve the relevant exhibition industry administration system, which can fully embody the value of the customer administration in the exhibition industry, and then expand on the practical research of the customer segmentation evaluation model in the exhibition customer administration.

\section{References}

[1] Zhi-long Ye \& Zhang-shu Huang. The Research of Online Member Customer Value Based on the New Three-dimensional Customer Segment Model [J]. Statistics \& Information Forum, 2016, 31(5): 96-101.

[2] Zheng-quan Cai, Zhi-feng Liu \& Lin Guan, et al. Assessment Method for Subdivision of Electric Power Customers and Reliability Value Based on Reliability Demand [J]. Guangdong Electric Power, 2015(5): 44-50.

[3] Yong-mei Gao, Chun-hua Ju \& Jiang-bo Zou. Personalized Service Construction Based on the Customers' Segmentation Model in the Telecom [J]. Mathematics in Practice and Theory, 2015(5):44-54.

[4] Cai-hua Song, Yong-cai Wang \& Yuan-juan Lan, et al. Analysis of data mining based customer classification model for electric power industry [J]. Modern Electronics Technique, 2014(14): 21-23.

[5] Yi Lian \& Shuo Yang. Customer value segmentation model based on loyalty and its application [J]. Commercial Times, 2016(14): 42-45.

[6] Chong-hui Guo \& Zuo-wei Zhao. Customer Segmentation and Change Mining Based on Customer Behavior for 4S Shop [J]. Journal of Industrial Engineering and Engineering Management, 2015, 29(4):18-26.

[7] Meng Zhao \& Jia-yin Qi. The Research of Customer Lifetime Value Based on the Combination of Customer Purchase's RFM and Customer Online Review's RFMP [J]. Statistics \& Information Forum, 2014, v.29; No.168(9):91-98.

[8] Pan-qiang Niu, Min Zhang \& Ben-qian Li. Research on the construction of evaluation index model of China's Convention and exhibition industry [J]. Modern Management Science, 2015(5):100-102. 